the washings from the Mahler-Atwater bomb. These values are not in such close agreement to the values in column (I) and it may be argued in explanation that the sulphur thus obtained represents the combustible sulphur. The values are almost without exception lower. The differences between the values in columns (I) and (3) are shown in column (6).

In column (4) the values have been obtained by means of the photometer as illustrated in Fig. 2.

The standard light $(\mathrm{L})$ is made to read through the precipitated material in the graduated tube (A), the lower end of which is submerged in the cup (B). By this means a lens effect is secured and the end point is made very sharp and distinct. Aside from the improved form of apparatus shown in Fig. 2, the chief modification of the process made use of in the present series was the use of a small amount of oxalic acid in conjunction with barium chloride, which precipitates the barium sulphate in a very nearly colloidal condition, at least it does not settle readily and is uniform in its action towards the transmission of light. The curve as shown in Fig. 3 affords a ready means for determining the weight of sulphur in milligrams to correspond with the depth of the solution in millimeters.

It cannot be expected that such a method will have the same degree of accuracy that should accompany a gravimetric method, but for technical purposes it is admirably adapted as a quick and ready process for determining the sulphur in the fusion residues from calorimetric determinations by the use of sodium peroxide. Comparison as between this method and the gravimetric fusion method of column ( $\mathrm{I}$ ) is shown in column (7).

It may be well to call attention to one advantage in this series over the tests made by Holliger, in that three times the number of coals are tested, sufficient to bring out any variations that inhere in the various processes. It should be borne in mind that the fusion method No. I yields the total sulphur, while the tendency of method No. 3 is to yield the burnable sulphur rather than the total sulphur. If this latter distinction were sharply drawn, that method would have an advantage. On the other hand, method No. I has the advantage of certainty of oxidation when conducted as herein described, and there can be no question about the completeness of the process. It is, therefore, given preference in the table and the others are arranged in the order of what seems to be their respective merits. The coals are widely distributed; their source, as may be seen by reference to the article on calorimetric values above referred to, is from Pennsylvania, West Virginia, Kentucky, Alabama, Maryland, Kansas, Indiana and Illinois.

UNIVERSITY OF IlLINOIS, URBANA, ILIINOIS.

\section{STUDIES IN THE USES OF FINELY DIVIDED SILICA. ${ }^{1}$}

By S. W. PARR, T. R. ERNest AND W. S. WiLIIAMs. Received August 7, 1909.

The extensive deposits of finely divided silica found in Southern Illinois have furnished, in very large measure, the incentive for some work in the Department of Applied Chemistry of the University of Illinois during the last two years. This work has consisted mostly of experiments on compounds such as are formed at steam temperatures between this material and lime.

It was found that bricks made in this way possessed, after steaming, good texture and strength. This suggested a series of experiments to determine the best ratio of lime to silica. Then the idea of making briquettes by moulding without pressure suggested itself, and with it came the question as to the best conditions for maximum strength. In the first case the briquettes were made by conipression and tested for crushing strength while in the second a cement briquette mould was used and briquettes were tested for tensile strength. In the first case the best lime silica ratio was found to be one mol. of lime to one of silica, while in the latter the best results were attained when 20 per cent. of lime was used with 80 per cent. of amorphous silica as is shown by the following tables:

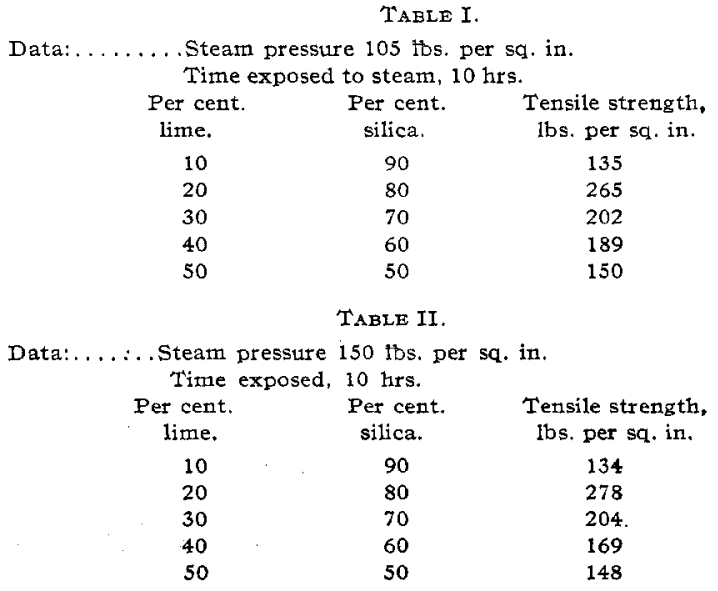

1 An examination of this material made some years ago showed it to be of chalky appearance sometimes stained by iron. It consists of 
TABLE III.

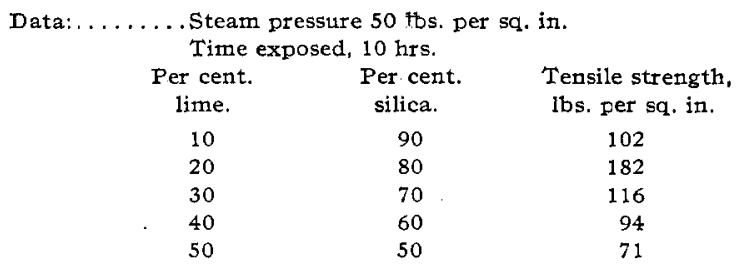

An attempt was made to ascertain whether or not pressure was needed to bring about this reaction, or whether it was caused by the heat of saturated steam together with the moisture. To do this, briquettes were made in the usual way and placed in a chamber that could be heated from without to a temperature corresponding to that of saturated steam at $1_{50}$ pounds pressure. Steam was then generated in a flask and superheated to the temperature of the chamber after which it was passed over the briquettes. The time of exposure varied from ten to forty-eight hours, but in no case was there any noticeable reaction. From this it was concluded that pressure as well as heat and moisture is required to bring about the reaction.

The effect of heat on these briquettes is rather interesting, as is shown by the following table:

$\begin{array}{ccc} & \begin{array}{c}\text { TABLE IV. } \\ \text { Drawn at tem- }\end{array} & \begin{array}{c}\text { Tensile strength, } \\ \text { Test number. } \\ \text { perature, }{ }^{\circ} \mathrm{C} .\end{array} \\ \begin{array}{ccc}\text { lbs. per sq. in. } \\ 0\end{array} & 20 & 278 \\ 1 & 300 & 45 \\ 2 & 400 & 0 \\ 3 & 500 & 101 \\ 4 & 600 & 131 \\ 5 & 700 & 124 \\ 6 & 750 & 27 \\ 7 & 800 & 71 \\ 8 & 850 & 186 \\ 9 & 1190 & 260 \\ 10 & 1390 & 263\end{array}$

As this behavior is not what one would expect, the work was repeated several times with substantially the same results.

After finding the best proportion in which to mix the lime and silica to give the best tensile strength, experiments were made in which other substances were introduced into the briquette. Magnesia was found to work about the same as lime. It was found that the introduction of about four parts of sharp sand into a mixture of equal parts of lime and silica (one part) gave a product with much higher tensile strength than when no sand was used.

minute particles of silica, from $50 \mathrm{~mm}$. to $0.2 \mathrm{~mm}$. in diameter, of crystalline structure, transparent and irregular in shape, loosely cemented together by a small amount of clay. An analysis showed: Moisture $0.15 \%$; silica, $98.00 \%$ magnesium oxide, $0.20 \%$; aluminium oxide, $1.21 \%$ undetermined, $0.44 \%$. - ED.
The effect of the addition of fibrous material was next studied, and the first to be tried was slag wool. The addition of varying per cents. of this material did not materially affect the strength until enough was added to dilute the original material so much that it resulted in a weakening of the bond. There appeared to be no union between the fiber and lime. A cheap grade of asbestos was tried next. The results of the tests are shown in the following table:

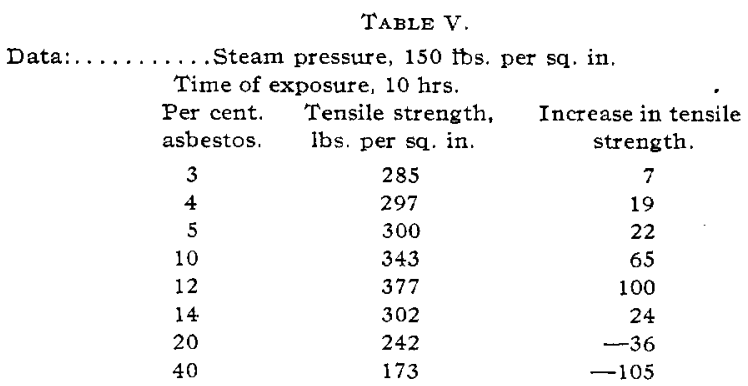

From the table it will be observed that the tensile strength rises with the addition of asbestos until I2 per cent. is added, when the drop is sudden. It will be noticed, too, that the strength of the material may be increased very materially by the addition of this fiber.

The eqfect of the addition of colloids was next studied. To the regular mixture of lime and silica (20 per cent. $\mathrm{CaO}$ to 80 per cent. $\mathrm{SiO}_{2}$ ), varying per cents. of sodium silicate and of Portland cement were added and the briquettes made and tested in the usual way. The results showed a decrease in the strength in every case, which in the case of the sodium silicate was about 66 per cent. of the original strength when only 5 per cent. was added.

Mixtures of lime and silica in the proportions for best tensile strength were found to possess good plasticity, this property being possessed in about the same degree as in the case of Georgia kaolin. This discovery led to an attempt to make a vase of this material. The regular mixture of lime and silica was used, enough water being added to give the best plasticity, and the vase moulded by hand in a plaster of Paris mould. When dry, the vase could be removed and the joints finished. When hardened by steam it had, when struck with a pencil, the true hard ring of vitrified clay biscuit. The material easily took the form and markings of the mould; there was no shrinkage that was noticeable and the color was a good clear white. No attempt was made to prepare a vase by making the mixture up with enough water so that it could 
be poured into a mould in the form of a slip, but there can be little doubt as to the possibility of making ware in this way. Small trials were also made by jiggering, which were very successful.

These experiments suggest the possibility of using this process for making architectural building material to be used in a way similar to terra cotta. The manufacturer of terra cotta has many obstacles to overcome in the process of burning. His ware may warp or be of the wrong color; it may shrink excessively or be defective in some other way. The manufacture of artificial stone that might be used similarly to terra cotta might be made, it seems, very advantageously by this process.

UNIVERSITY OF TILINOIS URBANA, ILL.

\section{CYANIDATION OF SILVER MINERALS.}

By THEO P, HOLT.

Received July I7, Igog.

This paper embodies some results of an investigation carried out during the past year, under the Wall Research Fellowship at the Utah State School of Mines. From a mechanical standpoint, the adaptation of the cyanide process from gold to silver ores has been very satisfactorily worked out, but chemically the development has been slow, and to quote a well-known writer, "It is difficult to differentiate between fact and fancy in dealing with the available evidence on the subject." It was with the hope of clearing up some of these mooted questions that this investigation was undertaken.

The experiments, which are represented in graphic form, were conducted in 8-oz. bottles. Ten of these were clamped in a suitable frame which was rotated by a small water motor. The speed of the motor was so regulated that the contents of the bottle would fall from one end to the other during each half revolution. The bottles were only partly filled so that an excess of oxygen was assured. The conditions favoring extraction are as good as obtained with air agitation, while variations due to gases present in the air, evaporation, etc,, are largely eliminated. Thus it is possible to estimate closely the consumption of cyanide due to the minerals present in the ore, and determine the amount of any metal dissolved from solution assays.

The value of experimental tables showing variations in results, secured by changes in treatment, is largely determined by the accuracy of our knowl- edge of the active agents at work in the test. In case several unknown factors enter into an experiment, we simply get a mass effect, and are unable to judge with safety the action of each agent. For this reason the significance of a set of tests on any particular ore is limited. The results on another ore of similar chemical composition may be quite different, due to mineralogical and physical differences. Thus it has been aptly said "that each ore is a problem in itself."

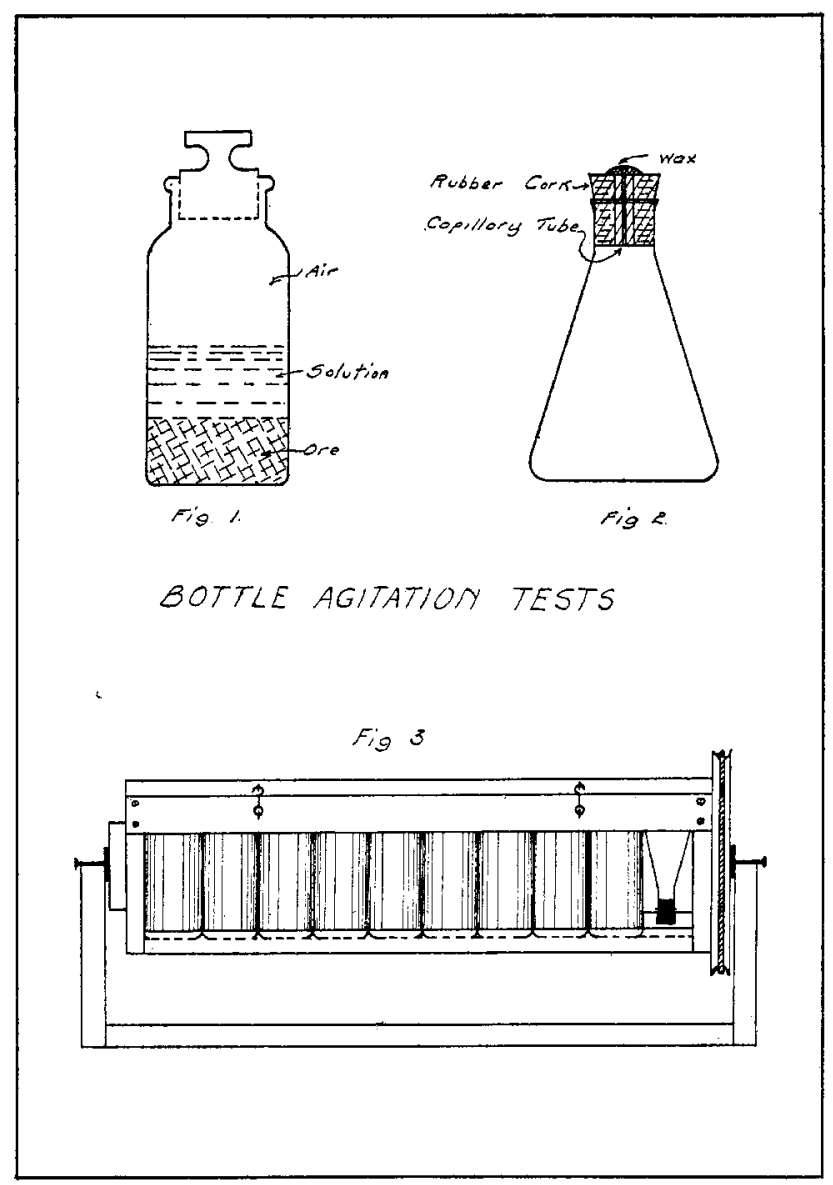

In consideration of the above facts I have made most of my experiments on chemical compounds and artificial ores of known mineralogical composition. Active agents, met with in cyanide practice, have been added singly. One example will serve to illustrate the general procedure. About I.6 gms. of a crystallized specimen of pyrargyrite $\left(\mathrm{Ag}_{3} \mathrm{SbS}_{3}\right)$ were crushed with a few grams of quartz sand in a porcelain mortar, to pass a roo-mesh screen. This was then mixed with $55^{\circ}$ grams of quartz sand, which had been ground on a stone bucking board to avoid the introduction of iron. After adding $1.6 \mathrm{gms}$. of lime the sample was thor- 